\title{
Sleep Go Away, I Don't Have Much Time Left to Live: Is Bedtime Procrastination Related to Perceived Time Left in Life?
}

\section{Uyku Seninle Uğrașamam, Yassayacak Çok Vaktim Kalmadı: Uykuyu Ertelemek Gelecek Zaman Algısıyla İlișkili mi?}

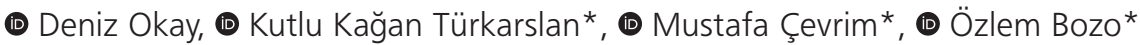 \\ TED University Faculty of Arts and Sciences, Department of Psychology, Ankara, Turkey \\ *Middle East Technical University Faculty of Arts and Sciences, Department of Psychology, Ankara, Turkey
}

\begin{abstract}
Objective: Sleep insufficiency is a common public health problem associated with various psychological and physical health outcomes. A recently proposed cause for sleep insufficiency is bedtime procrastination. Despite existing research about the concept, its underlying factors are mostly unclear. Considering the theoretical analogy between sleep time and the end of the day, the current study presents an explanation for bedtime procrastination. This study aims to examine the effect of future time perspective on bedtime procrastination and test the mediator role of purpose in life in this association.

Materials and Methods: A cross-sectional survey-based study was conducted with 317 participants. Each participant completed the measures of bedtime procrastination, future time perspective, purpose in life, self-control, circadian energy, and sleep quality.

Results: The analyses revealed that higher future time perspectives predicted lower bedtime procrastination; and purpose in life fully mediated the association. This effect remained significant after controlling the effects of self-control and circadian energy.

Conclusion: The results indicate that when people believe they have enough time in their life, they tend to procrastinate their bedtime less because they have a purpose for their future and focus less on momentary gains.

Keywords: Bedtime procrastination, future time perspective, purpose in life, sleep, sleep time
\end{abstract}

Öz

Amaç: Uyku problemleri, birçok psikolojik ve fizyolojik sağlık sorununu beraberinde getirmekte ve günden güne yaygınlaşmaktadır. Özellikle son yıllarda uyku problemlerinin sıklıkla araștııılan nedenlerinden biri olarak uyku vaktini erteleme davranışı öne çıkmaktadır. Görece yeni araştırılmaya başlanan bu konu hakkında yürütülmüş birtakım çalışmalar olmasına rağmen bu sorunun nedenlerine dair bilgiler hala belirsizdir. Uyku ve günün sonu arasında kurulmuş kuramsal benzerlik göz önünde bulundurularak bu araştırmada uykuyu erteleme davranışına yeni bir açıklama getirilmeye çalışılmıştır. Bu araştırmanın amacı, gelecek zaman algısının uykuyu erteleme üzerindeki etkisini, hayatın amacı değişkenin aracı rolünü de göz önünde bulundurarak incelemektir.

Gereç ve Yöntem: Kesitsel araştırma yöntemi kullanılarak yürütülmüş olan bu çalışmaya 317 kişi katılmıştır. Her katılımcı uyku vaktini erteleme, gelecek zaman algısı, hayatın amacı, öz-kontrol, biyolojik ritim ve uyku kalitesi ölçeklerini doldurmuştur.

Bulgular: Araştırmanın sonuçları, gelecek zaman algısındaki artışın uyku vaktini ertelemedeki azalmayı yordadığını ve bu ilişkide hayatın amacının aracı rolü olduğunu göstermiştir. Bu anlamlı etki, öz-kontrol ve biyolojik ritim kontrol edildikten sonra da devam etmiştir.

Sonuç: Araştırmanın sonuçlarına göre, insanlar hayatta yaşayacak yeterli vakitlerinin olduğuna inandıklarında kendilerine geleceğe dair hedefler koyarak anlık tatminleri erteliyor olabilir; bunun sonucunda da uykuyu daha az erteliyor olabilirler.

Anahtar Kelimeler: Uykuyu erteleme, gelecek zaman algısı, hayatın amacl, uyku, uyku vakti 


\section{Introduction}

A major public health problem of modern days is the lack of sufficient sleep $(1,2)$. Although sleep is critical for daily functioning, as well as for psychological and physical health (3-5), it has been reported that sleep durations of U.S. adults significantly decreased over the years (4). Based on the reports of National Sleep Foundation (6), almost half of the U.S. adults stated that changing their sleep schedules even for an hour affects them both physically and emotionally, yet only $30 \%$ and $38 \%$ of them followed a regular bedtime routine in weekdays and weekends, respectively.

Most of the studies about sleep psychology focused on sleep insufficiency in individuals with sleep disorders such as insomnia, hypersomnia, or sleep apnea. Yet, sleep insufficiency is also a common and escalating problem for the general population (7). One of the main reasons for insufficient sleep was reported as procrastination of bedtime (8). Bedtime procrastination was defined as the behavior of deliberately postponing bedtime without any accountable external reason (9). According to the study of Kroese et al. (1), $74 \%$ of the representative Dutch sample postponed their bedtime at least once a week.

Although it is a major cause of sleep insufficiency, procrastination of sleep is a rather new concept; and thereby, the data about it is very limited (9). Published heretofore literature highlighted its association with several constructs such as circadian chronotypes, i.e., people's genetic preference of morningness $(r=0.34)(10)$ or eveningness $(r=-0.39)(11)$ and aversive bedtime routines like brushing teeth or taking out contact lenses ( $r=0.31)(8)$. But the majority of the studies in this area considered bedtime procrastination as a selfcontrol dysfunction, i.e., the inability to resist distractions $(9,12)$. Hence, these studies revealed inconsistent correlations between bedtime procrastination and self-regulation problems ranging from low $(r=-0.11)$ to high $(r=-0.52)$. What confused researchers further was that procrastination behaviors happen when the task is aversive (e.g., doing homework or exercise, etc.), but going to bed is not considered as an aversive activity for many people (1). Therefore, despite existing research about bedtime procrastination, its underlying factors remained mostly unclear (2).

Recent studies revealed that people procrastinate sleep more when their days are filled with obligations since they believe they need that leisure time at night as a daily reward $(7,13)$. Although these studies explained bedtime procrastination again by individuals' difficulty in self-regulation, in the current research, we suggested an alternative explanation for it.

The present study puts forward the hypothesis that bedtime procrastination might be explained by individuals' subjective perception of time. Subjective perception of time, also known as the future time perspective, means how much time people believe they have left to live (14). According to the socioemotional selectivity theory (SST) people's preferences for activities and pursuit of goals depend on their subjective perception of time $(15,16)$. People might perceive their time left in life as limited ("My time is running out") or openended ("I have enough time ahead") $(14,16)$. When people believe their time is limited, they tend to search for immediate happiness and experiences at the moment; since their futureoriented goals are perceived as inaccessible $(17,18)$. On the other hand, when people perceive their time as open-ended, they tend to focus on their future-oriented goals and delay current emotional rewards (16).

There has been scarce literature published on the association of future time perspective with health-related behaviors. These studies mainly pointed out that a more future-oriented life promotes healthy practices and less risky behaviors. $(19,20)$. However, bedtime procrastination, as one of the health-related behaviors, has not been investigated in relation to future time perspective, yet. But as SST pointed out, the endings in life (e.g., graduation, relocation, old age) remind people of their remaining time in life (21). Considering this, sleep time might also prime people to think about their remaining time because it is considered as the end of the day. Therefore, it can be proposed that sleep-related behaviors, one being the bedtime procrastination, are also affected by people's subjective perception of time.

The proposed association between bedtime procrastination and future time perspective might be influenced by purpose in life (PIL) because the relation between PIL and future time perspective is well-documented in the literature (e.g., 22). PIL is mainly defined as a central life aim organizing people's goals and behaviors and providing them with a sense of direction in life, thereby making their life more meaningful (23-25). According to Frankl (24), aiming at future means aiming at a goal, and if the future is blocked or perceived as limited, then for those people, life loses its meaning. Therefore, those people are more likely to devote themselves to present-day activities and immediate outcomes (14). On the contrary, when people believe they have a future, they may see their future as an area for new meaning and possibilities $(22,24)$. Even though these people may also live in the present, they are more attuned to their future for new opportunities; and establish more futureoriented goals (22). Since bedtime procrastination is considered as a daily reward for some people, who prioritize present over future (7), this construct is hypothesized to change as a function of future time perspective and PIL.

In light of the information given above, the current study proposes that the behavior of bedtime procrastination is influenced by people's subjective perception of time. Those who believe they do not have much time in life may have no goals for their future and thereby may focus on their immediate happiness and present rewards. On the other hand, those who believe they have enough time in their life may focus on their future and establish a life goal for themselves; and thereby, they may see no importance in procrastinating their bedtime. Thus, the current research hypothesized that (1) higher future time perspective would predict lower bedtime procrastination, and (2) PIL would mediate the relation between future time perspective and bedtime procrastination. 


\section{Materials and Methods}

\section{Participants}

The sample of the current study consisted of 317 participants. They were recruited from the department's subject pool, SONA, which is an online platform enabling university students to participate in studies in return of bonus points for their courses. The details of the demographic characteristics of the participants can be seen in Table 1 .

\section{Measures}

Bedtime procrastination scale (BPS): BPS was developed by Kroese et al. (9) to assess bedtime habits and procrastination. It includes 9 self-report items. The participants rate these items on a 5-point Likert scale ranging from 1 (never) to 5 (always). Higher scores on the scale indicate more bedtime procrastination. Sample items are "I easily get distracted by things when I actually would like to go to bed" and "I want to go to bed on time but I just don't". According to explanatory factor analysis, it is a single-factor scale (Eigenvalue=5.57). Higher correlations between sleep outcomes and BPS ( $\left.r_{\text {range }}=0.46-0.61\right)$ compared to the correlations between the former and general procrastination ( $r_{\text {range }}=-0.19-0.37$ ) indicate its validity (9). The Turkish adaptation of the scale was carried out by Yılmaz Dinç et al. (26). Confirmatory factor analysis yielded a single factor explaining $60.10 \%$ of the total variance. The Cronbach's alpha value of the Turkish version was 0.71 . In our current study, the internal consistency of the scale was 0.91 .

Future time perspective scale (FTP): Carstensen and Lang (27) developed the FTP to measure people's subjective perception of time with 10 items. The participants rate the items on a 5-point

\begin{tabular}{|c|c|c|}
\hline & $\begin{array}{l}\text { Frequency/ } \\
\text { mean }\end{array}$ & $\begin{array}{l}\text { Percentage } \\
(\%) / S D\end{array}$ \\
\hline Age & 21.78 & 3.94 \\
\hline \multicolumn{3}{|l|}{ Gender } \\
\hline Female & 250 & 78.86 \\
\hline Male & 67 & 21.13 \\
\hline \multicolumn{3}{|c|}{ Marital status } \\
\hline Single & 312 & 98.42 \\
\hline Married & 5 & 1.57 \\
\hline \multicolumn{3}{|l|}{ Children } \\
\hline Yes & 3 & 0.94 \\
\hline No & 314 & 99.05 \\
\hline \multicolumn{3}{|c|}{ Employment } \\
\hline Yes & 23 & 7.25 \\
\hline No & 294 & 92.74 \\
\hline \multicolumn{3}{|c|}{ Socio-economic status } \\
\hline Very high & 3 & 0.94 \\
\hline High & 25 & 7.88 \\
\hline Middle & 243 & 76.65 \\
\hline Low & 39 & 12.30 \\
\hline Very low & 7 & 2.20 \\
\hline \multicolumn{3}{|c|}{ SD: Standard deviation } \\
\hline
\end{tabular}

Likert scale ranging from 1 (very untrue) to 5 (very true). Higher scores indicate more extended future time perspective. Sample items include "Many opportunities await me in the future" and "As I get older, I begin to experience time as limited". The internal consistency for the FTP was reported as 0.92 in the original study. The FTP was translated into Turkish by Edwards (28). The Cronbach's alpha coefficient for the Turkish version was 0.90 . Its positive correlations with the life orientation test and planful subscale of the attitudes towards the future scale (AFTS); and negative correlation with the anxious subscale of the AFTS indicated construct validity of the Turkish FTP. In our study, the internal consistency reliability coefficient of FTP was 0.86 .

Purpose in life test (PILT): The PILT was constructed by Crumbaugh and Maholick (23). It is a two-subscale, 20-item scale, and one of its subscales assesses the level of PIL. Higher score on this subscale means that the person has higher sense of purpose and meaning in life. The items are rated on a 7-point Likert scale. Sample items consisted "Life to me seems: completely routine/always exciting" and "As I view the world in relation to my life, the world: Completely confuses me/its meaningfully with my life". As an indication of discriminant validity, PILT could successfully differentiate psychiatric patients from healthy individuals (29). The PILT was translated into Turkish by Kıraç (30); four original items were discarded from Turkish version of the PILT since psychometric properties of them were insufficient. The Cronbach's alpha coefficient of the Turkish PILT was 0.91 and the split-half reliability value of the scale was 0.92 . Explanatory factor analyses showed the Turkish scale has three factors, namely meaning and purpose, quality of life, and freedom. The threefactor structure explained $58.4 \%$ of the total variance (30). For the current sample, the internal consistency reliability coefficient of the scale was 0.92 .

Brief self control scale (BSCS): The BSCS is a short version of the self control scale developed by Tangney et al. (31). The scale aims to measure "The ability to override or change one's inner responses, as well as to interrupt undesired behavioral tendencies and refrain from acting on them", in other words, self-control (31, p274). The 13 items of the scale are rated on a 5-point Likert scale, from 1 (not at all like me) to 5 (very much like me). A high BSCS score means that the person has high self-control. Sample items are "I refuse things that are bad for me" and "I have a hard time breaking bad habits". The Turkish adaptation of the BSCS was done by Nebioglu et al. (32). The internal consistency of the Turkish form was 0.83, while the test-retest reliability of the scale was 0.88 . Negative correlations of BSCS with the impulsivity subscale of The Barratt impulsiveness scale-11 as well as controlling negative body responses and anger management subscales of emotional management skills scale evinced the Turkish BSCS's concurrent validity. In addition, as an indication of discriminant validity, the BSCS could successfully differentiate healthy groups from individuals diagnosed with bipolar disorder (32). As previous studies indicated an association between procrastination and self-control, in the current study, BSCS was utilized to measure 
one of the control variables. For the present sample, the Cronbach's alpha value was 0.84 .

The circadian energy scale (CIRENS): The CIRENS was developed by Ottoni et al. (33) to assess chronotypes. The scale has three basic items assessing energy levels at morning, evening, and afternoon (optionally). The participants rate their energy levels on a 5-point scale that ranges from 1 (very low) to 5 (very high). The items of the scale are "In general, how is your energy level in the morning" and "In general, how is your energy level in the evening". One can measure chronotype simply by subtracting the morning energy scores from the evening energy scores. The scores lower than -2 indicate morning type, the scores between -1 and 1 signify neither-type, finally the scores higher than 2 denote evening type. Ottoni et al. (33) found that the CIRENS had 0.70 correlation with the morningness eveningness scale. Acknowledging the robust relationship between sleep related variables and circadian chronotypes in the literature, in our study, the two items CIRENS was used to determine participants' chronotype and to enter it to the analyses as other control variable.

Pittsburgh sleep quality index (PSQI): Buysse et al. (34) constructed the PSQI to assess sleep characteristics and quality over the past month. PSQI consists of 24 items, and the first 19 are in self-report form. Since the last 5 items are rated by the participants' sleep partner, they may be excluded. Participants are asked to rate these 19 items on a 4-point Likert scale ranging from 0 to 3 . A score of 5 and lower from PSQI signals good sleep quality, whereas the scores higher than 5 imply that sleep quality get poorer. Sample items of index included "During the past month, what time have you usually gone to bed at night?" and "During the past month, how would you rate your sleep quality overall?". The original scale has 0.80 and 0.85 values for internal consistency reliability and test-retest reliability (for 28-days interval) respectively. The Cronbach's alpha value of Turkish PSQI was 0.80, while test-retest reliability correlation value was 0.98 (35). In this study the PSQI was used to gather descriptive information about sleep characteristics, patterns, and quality of the participants. For the present sample, the alpha value for PSQI was 0.79 .

\section{Procedure}

The data used in the present study is a part of a larger dataset. After the ethical approval was obtained from the institutional review board (protocol number: 2018-SOS034), all instruments were uploaded to a secure online data collection system, and participants were invited to the study via the department's subject pool. Instructions about the study purposes, confidentiality procedures, and their participant rights (refusal to participate or withdrawal from the research) were provided. The questionnaires were presented to participants in a counterbalanced order. The application of the questionnaires took nearly 20 minutes.

\section{Statistical Analysis}

All analyses were conducted using SPSS 25. To test the hypotheses that higher future time perspective would predict lower bedtime procrastination and PIL would mediate the relationship between future time perspective and bedtime procrastination, SPSS macro "indirect" with bootstrapping procedure based on 10000 bootstrapped resamples was used (36). Future time perspective (independent variable), bedtime procrastination (dependent variable), and PIL (mediating variable) were included in the mediation model. A second model, in which self-control and circadian chronotypes were controlled, was also tested.

\section{Results}

The descriptive statistics of sleep duration, sleep latency, and subjective sleep quality are presented in Table 2. The PSQI scores yielded that the average sleep duration of the participants was 7.30 hours [standard deviation (SD)=1.18]. Only $4.73 \%$ of the participants reported having less than 5 hours of sleep, and $3.78 \%$ of the participants reported having 9-10 hours of sleep. After going to bed, participants were able to fall asleep in 30.30 minutes $(S D=25.13)$ on average. In terms of subjective sleep quality, the majority of the participants reported their sleep quality as very good or fairly good (55.84\%). More than a third of the participants (35.65\%) reported that they have difficulty to remain awake during daily activities at least once in a week.

\begin{tabular}{|c|c|c|c|c|c|c|c|c|c|c|c|}
\hline \multicolumn{3}{|c|}{ Sleep duration } & \multicolumn{3}{|c|}{ Sleep latency } & \multicolumn{3}{|c|}{ Subjective sleep quality } & \multicolumn{3}{|c|}{ Difficulty to remain awake } \\
\hline & Frequency & $\%$ & & Frequency & $\%$ & & Frequency & $\%$ & & Frequency & $\%$ \\
\hline$<5$ hrs & 15 & 4.73 & $0-15$ mins & 124 & 39.11 & Very good & 16 & 5.05 & $\begin{array}{l}\text { Not during the } \\
\text { past month }\end{array}$ & 106 & 33.44 \\
\hline $5-6 \mathrm{hrs}$ & 45 & 14.19 & $15-30$ mins & 108 & 34.06 & Fairly good & 161 & 50.79 & $\begin{array}{l}\text { Less than once } \\
\text { a week }\end{array}$ & 98 & 30.91 \\
\hline $6-7 \mathrm{hrs}$ & 86 & 27.12 & $30-60$ mins & 62 & 19.55 & Fairly bad & 126 & 39.75 & $\begin{array}{l}\text { Once or twice a } \\
\text { week }\end{array}$ & 80 & 25.24 \\
\hline $7-8 \mathrm{hrs}$ & 122 & 38.48 & $>60$ mins & 23 & 7.25 & Very bad & 14 & 4.41 & $\begin{array}{l}\text { Three or more } \\
\text { times week }\end{array}$ & 33 & 10.41 \\
\hline $8-9$ hrs & 37 & 11.67 & - & - & - & - & - & - & - & - & - \\
\hline 9-10 hrs & 4 & 1.26 & - & - & - & - & - & - & - & - & - \\
\hline$>10 \mathrm{hrs}$ & 8 & 2.52 & - & - & - & - & - & - & - & - & - \\
\hline
\end{tabular}


Descriptive statistics for and Pearson correlation coefficients among age, circadian energy and self-control, future time perspective, PIL and bedtime are presented in Table 3 . The correlations between the main study variables were in expected directions. There was a small to medium negative correlation between future time perspective and bedtime procrastination $(r=-0.26, p<0.001)$. In other words, the participants who believed they still have much time in life tended to procrastinate bedtime less. Moreover, future time perspective and PIL had medium to large positive correlation $(r=0.57, p<0.001)$, meaning that the individuals who believed they have much time in life were also likely to find their life more purposeful.

\section{Mediation Analysis}

The results of the mediation analysis can be seen in Table 4. The direct effect of future time perspective on bedtime procrastination was not significant $[b=-0.05$, boot $\mathrm{SE}=0.05, \mathrm{p}=0.34,95 \%$ confidence interval $(\mathrm{Cl})(-0.14$, $0.05)]$. However, the bootstrapped unstandardized indirect effect was significant $[b=-0.15$, boot $S E=0.03, p<0.001$, $95 \% \mathrm{Cl}[(-0.21,-0.10)]$. Hence, PIL fully mediated the future time perspective-bedtime procrastination association. The overall model was significant $[F(2,314)=28.51, p<0.001]$, and it accounted for $15 \%$ of the variance in bedtime procrastination. The relations in the mediation model are illustrated in Figure 1. After controlling for age, self-control and circadian energy, PIL still fully mediated the relation between future time perspective and bedtime procrastination [The direct effect: $b=-0.08$, boot $S E=0.05, p=0.07,95 \% \mathrm{Cl}$ $(-0.17,-0.01)]$.

\section{Discussion}

The current study aimed to provide an alternative explanation to the phenomenon of bedtime procrastination, which is generally conceptualized as a self-regulation dysfunction (e.g. 37). Considering that general procrastination behaviors provide some benefits to the person since it includes ceasing to do the aversive task (1), for some individuals, there might also be a possible gain in this type of procrastination behavior. Following this idea, the current study investigated the effect of future time perspective on bedtime procrastination, and the mediator role of PIL in this association. The proposed hypotheses were confirmed by the findings. Accordingly, the total effect of future time perspective on bedtime procrastination was significant. In other words, having higher future time perspective predicted lower bedtime procrastination behaviors. This finding suggested that people who believe they have enough time in life are less likely to procrastinate their bedtime. On the other hand, people who believed they have limited time tended to procrastinate more, perhaps to enjoy their remaining time to its fullest and not to waste it with sleeping. Moreover, PIL fully mediated the effect of future time perspective on bedtime procrastination. This indirect effect remained significant even after controlling self-control and circadian energy. This result indicated that the relation between future time perspective and bedtime procrastination could be better explained via the concept of PIL. As it was stated in the literature, when individuals believe they have a future, they are able to construct a purpose and follow the path leading to that purpose $(22,24)$. For these people, the future goals are prioritized over their present (14). According to MacKenzie and Baumeister (38), PIL represents people's goals for the future; and people engage and organize their presentday activities to reach these goals in the future, even if those

\begin{tabular}{|c|c|c|c|c|c|c|c|c|c|}
\hline Variables & 1 & 2 & 3 & 4 & 5 & M & SD & Min & Max \\
\hline 1) Age & - & & & & & 21.78 & 3.94 & 18.00 & 58.00 \\
\hline 3) Self control & $0.26^{* * *}$ & $-0.20^{* * *}$ & & & & 41.07 & 8.15 & 17.00 & 63.00 \\
\hline 4) Future time perspective & -0.06 & -0.01 & $0.25^{\star \star *}$ & & & 46.11 & 9.72 & 15.00 & 70.00 \\
\hline 5) Purpose in life & $0.20^{* * *}$ & $-0.16^{* *}$ & $0.51^{* * *}$ & $0.57^{* * *}$ & & 91.19 & 19.16 & 39.00 & 135.00 \\
\hline \multicolumn{6}{|c|}{${ }^{*} \mathrm{p}<0.05,{ }^{* *} \mathrm{p}<0.01,{ }^{* * *} \mathrm{p}<0.001$, SD: Standard deviation } & & & & \\
\hline
\end{tabular}

\begin{tabular}{|c|c|c|c|c|c|}
\hline & \multirow[t]{2}{*}{ B } & \multirow[t]{2}{*}{$\mathbf{t}$} & \multirow[t]{2}{*}{$\mathbf{p}$} & \multicolumn{2}{|l|}{$95 \% \mathrm{Cl}$} \\
\hline & & & & Lower & Upper \\
\hline Mediation path a & 1.11 & 12.14 & $<0.001$ & 0.93 & 1.29 \\
\hline Mediation path $\mathrm{b}$ & -0.20 & -4.79 & $<0.001$ & -0.28 & -0.12 \\
\hline Total effect, path c (future time perspective on bedtime procrastination with purpose in life) & -0.20 & -4.79 & $<0.001$ & -0.28 & -0.12 \\
\hline Direct effect, path $c^{\prime}$ (future time perspective on bedtime procrastination) & -0.05 & -0.95 & 0.34 & -0.14 & 0.05 \\
\hline $\begin{array}{l}\text { Indirect effect bootstrapped } \\
95 \% \mathrm{Cl}\end{array}$ & -0.15 & - & - & -0.21 & -0.09 \\
\hline
\end{tabular}






Note. ${ }^{*} p<.001$

Figure 1. The regression coefficient (unstandardized) fot the relationship between future time perspective and bedtime procrastination in mediation of purpose in life

activities are unpleasant. Therefore, it can be argued that our present-day activities are closely related to future outcomes. In terms of bedtime procrastination, it might be suggested that those people, who think that they have plenty of time ahead and are able to establish a purpose, perceive their future time just as rewarding or even more rewarding than their present time. Thereby, these individuals are likely to focus on the upcoming days, which will lead them to their purpose and might see procrastination of sleep unnecessary. On the other hand, when people believe their time in life is limited, they seem not to be able to create a future goal or plan, i.e., the purpose for their life, and thus, might prefer to engage in present-day activities to gain emotional satisfaction at least for that moment.

The present researchers' attempt to explain bedtime procrastination through time perception and PIL provided an existential approach to conceptualize the concept of bedtime procrastination further. In many previous studies, sleep behaviors were investigated in relation to several existential constructs such as death anxiety (10), meaning in life (39), and existential well-being (40). Although sleep is generally formulated from the medical or behavioral perspectives, the importance of studying sleep from the perspective of existential psychology is re-emphasized with the present findings. Considering the vital importance of sleep for human life, understanding its meaning from a broader perspective seems crucial.

\section{Study Limitations}

Despite its contributions, the present study is not without its limitations. First, due to its cross-sectional nature, the present findings do not imply any causality between future time perspective and bedtime procrastination. Second, most of the current participants were female, and the mean age of the sample was 21.78. Since age (14) and PIL (41) are crucial factors impacting on future time perspective, further studies with a more representative sample should be conducted.

\section{Conclusion}

Overall, this was an exploratory study aiming to examine the relationship between subjective perception of time and bedtime procrastination, and the mediator role of PIL in this relation. These findings offered several new explanations for the recently investigated concept of bedtime procrastination. Mainly, these results suggest that bedtime procrastination is not simply a selfregulatory dysfunction, but it may be perceived as a behavior that is related to our perceived time left in time and our our purpose in life. It is expected that further studies will expand these findings, and especially qualitative studies could be valuable in terms of clearly highlighting the motives, particularly the existential motives, of people who tend to procrastinate their bedtime.

\section{Ethics}

Ethics Committee Approval: The ethical approval of this study was obtained from the Middle East Technical University, Human Subject Ethics Committee (protocol number: 2018-SOS-034).

Informed Consent: Informed consent was approved by all the participants through Qualtrics Online Survey Software.

Peer-review: Externally and internally peer-reviewed.

\section{Authorship Contributions}

Design: D.O., K.K.T., M.Ç., Ö.B., Data Collection and Processing: D.O., K.K.T., M.Ç., Analysis and Interpretation: D.O., K.K.T., M.Ç., Ö.B., Literature Search: D.O., K.K.T., M.Ç., Writing: D.O., K.K.T., M.Ç., Ö.B.

Conflict of Interest: No conflict of interest was declared by the authors.

Financial Disclosure: The authors declared that this study received no financial support.

\section{References}

1. Kroese FM, Nauts S, Kamphorst BA, Anderson JH, De Ridder TD. Bedtime procrastination: a behavioral perspective on sleep 
insufficiency. In: Sirois FM, Pychyl TA (eds). Procrastination, health and well-being. Academic Press, 2016;93-119. Available from: https://www.sciencedirect.com/science/article/pii/ B9780128028629000050?via\%3Dihub

2. Valshtein TJ, Oettingen G, Gollwitzer PM. Using mental contrasting with implementation intentions to reduce bedtime procrastination: two randomised trials. Psychol Health 2020;35:275-301.

3. Herzog-Krzywoszanska R, Krzywoszanski L. Bedtime procrastination, sleep-related behaviors, and demographic factors in an online survey on a Polish sample. Front Neurosci 2019;13:963.

4. Krueger PM, Friedman EM. Sleep duration in the United States: a cross-sectional population-based study. Am J Epidemiol 2009;169:1052-63.

5. Strine TW, Chapman DP. Associations of frequent sleep insufficiency with health-related quality of life and health behaviors. Sleep Med 2005;6:23-7.

6. Sleep in America Poll [Internet]. Sleep Foundation. 2019 [cited 2021 Apr 10]. Available from: National Sleep Foundation (2019). Sleep in America Poll. https://www.sleepfoundation.org/

7. Kamphorst BA, Nauts S, De Ridder DTD, Anderson JH. Too depleted to turn in: the relevance of end-of-the-day resource depletion for reducing bedtime procrastination. Front Psychol 2018;9:252.

8. Nauts S, Kamphorst BA, Sutu AE, Poortvliet R, Anderson JH. Aversive bedtime routines as a precursor to bedtime procrastination. Eur J Health Psychol 2016;18:80-5.

9. Kroese FM, De Ridder DTD, Evers C, Adriaanse MA. Bedtime procrastination: introducing a new area of procrastination. Front Psychol 2014;5:611.

10. Türkarslan KK, Okay D, Çevrim M, Bozo Ö. Life is short, stay awake: death anxiety and bedtime procrastination. J Gen Psychol 2020;147:43-61.

11. Kadzikowska-Wrzosek R. Insufficient sleep among adolescents: the role of bedtime procrastination, chronotype and autonomous vs. Controlled motivational regulations. Curr Psychol 2020;39:1031-40.

12. Exelmans L, Van den BulckJ. "Glued to the tube": the interplay between self-control, evening television viewing, and bedtime procrastination. Communic Res 2017. doi: 10.1177/0093650216686877

13. Nauts S, Kamphorst BA, Stut W, De Ridder DTD, Anderson JH. The explanations people give for going to bed late: A qualitative study of the varieties of bedtime procrastination. Behav Sleep Med 2018; 17:753-62.

14. Lang FR, Carstensen LL. Time counts: future time perspective, goals, and social relationships. Psychol Aging 2002;17:125-39.

15. Allemand M, Hill PL, Ghaemmaghami P, Martin M. Forgivingness and subjective well-being in adulthood: the moderating role of future time perspective. J Res Pers 2012;46:32-9.

16. Carstensen LL, Isaacowitz DM, Charles ST. Taking time seriously. A theory of socioemotional selectivity. Am Psychol 1999;54:165-81.

17. Fung $\mathrm{HH}$, Carstensen LL. Motivational changes in response to blocked goals and foreshortened time: testing alternatives to socioemotional selectivity theory. Psychol Aging 2004;19:68-78.

18. Hicks JA, Trent J, Davis WE, King LA. Positive affect, meaning in life, and future time perspective: an application of socioemotional selectivity theory. Psychol Aging 2012;27:181-9.

19. Keough KA, Zimbardo PG, Boyd JN. Who's smoking, drinking, and using drugs? Time perspective as a predictor of substance use. Basic Appl Soc Psych 1999;21:149-64.

20. Boyd JN, Zimbardo PG. Time perspective, health, and risk taking. In: Strathman A, Joireman J (eds). Lawrence Erlbaum Associates, Inc, Publishers, 2005;85-107.
21. Fung HH, Carstensen LL. Goals change when life's fragility is primed: lessons learned from older adults, the September 11 attacks and SARS. Soc Cogn 2006;24:248-78. doi: /10.1521/soco.2006.24.3.248

22. Rappaport H, Fossler RJ, Bross LS, Gilden D. Future time, death anxiety, and life purpose among older adults. Death Stud 1993;17:369-79.

23. Crumbaugh JC, Maholick LT. An experimental study in existentialism: the psychometric approach to Frankl's concept of noogenic neurosis. J Clin Psychol 1964;20:200-7.

24. FrankI VE. Man's search for meaning: an introduction to logotherapy. Washington, Square Press Pocket Books, 1984.

25. Keyes CLM, Lopez SJ. Toward a science of mental health: positive directions in diagnosis and interventions. In: Snyder CR, Lopez SI (eds). Handbook of Positive Psychology. New York, NY: Oxford, 2002:45-59.

26. Yılmaz Dinç S, Koçhan K, Zat Z. The validity and reliability of The Bedtime Procrastination Scale. Int J Humanit Soc Sci 2016;5:57-62. Available from: https://www.ijhssi.org/v5i9(version\%202).html

27. Carstensen LL, Lang FR. Future time perspective scale. Stanford, CA: Stanford University, 1996.

28. Edwards AG. Relationship between future time orientation, adaptive self-regulation, and well-being: self-type and age related differences. Ankara, Middle East Technical University, 2008.

29. Crumbaugh JC. Cross-validation of purpose-in-life test based on Frankl's concepts. J Individ Psychol 1968;24:74-81.

30. Kıraç F. Dindarlık Eğilimi, varoluşsal kaygı ve psikolojik sağlık. Ankara, Ankara Üniversitesi, 2007.

31. Tangney JP, Baumeister RF, Boone AL. High self-control predicts good adjustment, less pathology, better grades, and interpersonal success. J Pers 2004;72:271-324.

32. Nebioglu M, Konuk N, Akbaba S, Eroglu Y. The investigation of validity and reliability of the Turkish version of the brief self-control scale. Bulletin of Clinical Psychopharmacology 2012;22:340-51.

33. Ottoni GL, Antoniolli E, Lara DR. The Circadian Energy Scale (CIRENS): two simple questions for a reliable chronotype measurement based on energy. Chronobiol Int 2011;28:229-37.

34. Buysse DJ, Reynolds CF, Monk TH, Berman SR, Kupfer DJ. The Pittsburgh Sleep Quality Index: a new instrument for psychiatric practice and research. Psychiatry Res 1989;28:193-213.

35. Ağargün MY, Kara $H$, Anlar Ö. Pittsburgh uyku kalitesi indeksinin geçerliği ve güvenirliği Validity \& reliability of the pittsburgh sleep quality index in Turkish sample. Turk Psikiyatri Derg 1996;7:107-15.

36. Hayes AF. The simple mediation model. In: Hayes AF (ed). Introduction to mediation, moderation, and conditional process analysis: a regression-based approach. Guilford, New York, 2017;77-112.

37. Kühnel J, Syrek C], Dreher A. Why don't you go to bed on time? A daily diary study on the relationships between chronotype, selfcontrol resources and the phenomenon of bedtime procrastination. Front Psychol 2018;9:77.

38. MacKenzie MJ, Baumeister RF. Meaning in life: Nature, needs, and myths. In: Batthyany A, Russo-Netzer P (eds). Meaning in positive and existential psychology. Springer, New York, 2014;25-37.

39. Kim ES, Hershner SD, Strecher VJ. Purpose in life and incidence of sleep disturbances. J Behav Med 2015;38:590-7.

40. Phillips KD, Mock KS, Bopp CM, Dudgeon WA, Hand GA. Spiritual well-being, sleep disturbance, and mental and physical health status in HIV-infected individuals. Issues Ment Health Nurs 2006;27:125-39.

41. Steger MF, Oishi S, Kashdan TB. Meaning in life across the life span: levels and correlates of meaning in life from emerging adulthood to older adulthood. J Posit Psychol 2009;4:43-52. 